\title{
Examining and Predicting Ethnocultural Empathy of Preservice Classroom Teachers
}

\author{
Tugay Tutkun \\ Faculty of Education, Çanakkale Onsekiz Mart University, Çanakkale, Turkey
}

Copyright $\mathrm{C} 2019$ by authors, all rights reserved. Authors agree that this article remains permanently open access under the terms of the Creative Commons Attribution License 4.0 International License

\begin{abstract}
This study aims to define and examine ethnocultural empathy level of preservice classroom teachers. The research design of this study was non-experimental and causal-comparative, which seeks to find relationships between independent and dependent variables after an action or event occurred. Participants were 434 preservice classroom teachers studying in Primary School Education Programme in the Department of Elementary Education at Çanakkale Onsekiz Mart University in the academic year of 2017-2018. Turkish version of The Scale of Ethnocultural Empathy (TSEE), which was initially developed by Wang, et al. [1] and then adopted to Turkish language by Özdikmenli-Demir \& Demir [2] was conducted to measure ethnocultural empathy level of preservice classroom teachers. Results showed that ethnocultural empathy level of preservice teachers differed by gender, grade level, ethnic origin, family income and place of growth. Only three predictors; 'being experienced in multicultural environments', 'grade level' and 'being in the majority group' showed significance in the regression equation in this study.
\end{abstract}

Keywords Ethnocultural, Empathy, Classroom Teachers

\section{Introduction}

Beginning with the industrial age and intensifying in recent decades most countries and cities in the countries have witnessed a considerable and growing multi-ethnic migratory flow resulting in not only cultural and economic enrichment of countries but also episodes of intolerance, conflict and underlying social tension [3]. Due to these increases in immigration, globalization and international business people from different cultures are interacting more frequently both on a personal and professional level [4]. Thus, the phenomenon; empathy, more specifically, cultural empathy has become increasingly important in terms of understanding and resolving such problematic situations based on intolerance, conflict and social tension between cultures. It is thought that cultural empathy will help to establish softer and more pleasant interactions and working relationships.

As a Greek word "empatheia", empathy, means understanding others by entering in their world, or "standing in somebody else's shoes" [5]. Roughly, the term 'empathy' could be defined as the capacity of understanding or feeling what another person is experiencing from within their frame of reference, it reflects the capacity to place oneself in another's position [6]. In another words, it is the intellectual ability of taking the role or perspective of another person and emotional response to another person with the same emotional display [7].

Håkansson [8] stated four themes appearing repeatedly in the empathy literature seemed to be central to the phenomenon; understanding, emotion, perceived similarity, and concern for the other's well-being. Understanding is central to the empathy process as most of the definitions reflects, which involves the other's thoughts, feelings, desires, beliefs, situation, perspective, or experiences. Emotion is also viewed as a crucial factor on the part of the empathizer. Although empathy has both cognitive and emotional components, recent studies suggest that emotional components in the empathizer's experiences of empathy reflect a fuller and more meaningful relational experience than cognitive understanding alone [9]. Perceived similarity is another key concept facilitating empathic responses, which reflects the relevance of the empathizer's previous similar experiences for empathy. The underlying principle behind is that target's situation reminds of one's similar experiences and evoke the emotions that match the target's situation. More generally, empathizers who believe that they are similar to the other individual exhibit more empathic reactions than those who do not believe they are similar [9]. Ethnics and culture are among the primary factors influencing the psychological similarity so that empathy. Particularly, people usually feel more empathetic towards the ones who are in the same ethnic or cultural group with them than the ones who are 
not. Concern for the other's well-being, namely; altruism is also closely related to the empathy. People tend to help others more frequently by empathic concern that appears to be an altruistically motivated effort to improve the other's well-being. Empathy is also considered as the source of altruism since it evokes altruistic motivation. Moral principles are also related to empathy. Håkansson \& Montgomery [9] express that empathic feelings and moral principles seem to complement each other in order to produce moral behavior. Similarly, Hoffman states that moral principles seem to lack the motivating force for people to care for others without empathy [10].

Differing from the traditional empathy, a new type of empathy called "cultural empathy" was defined and theorized by some researchers during the last two decades. Although there are numerous definitions of culture in social fields such as psychology, anthropology, education etc., basically, culture could be defined as the shared norms, customs, beliefs, attitudes, and values of the individuals that have been accumulated in a society over time. In this context, cultural empathy is the appropriate understanding of a culture's values and beliefs but it is not sympathy with agreement with or identification with a specific culture [5]. It is different than mixing your own thoughts and actions with others it is an effort to see the world through another's eyes, hearing as they might hear and experiencing their internal world [11]. Simply, cultural empathy is "having an appreciation and consideration of the differences and similarities of another culture in comparison to one's own" [4]. Ridley and Lingle [12] defined cultural empathy as a "learned ability" which can be further characterized by its multidimensionality and interpersonal nature.

Derived from the term cultural empathy, Wang et al. [1] coined a new term; ethnocultural empathy and operationalized the concept by developing a scale to measure it. They defined ethnocultural empathy as the empathy directed toward people from racial and ethnic groups who are different from one's own ethno-cultural group [1]. Criticizing this view of Wang, et al. [1], ethnocultural empathy as existing only within the empathizing person, Rasoal, Eklund \& Hansen [13] expands the conceptualization of the term to include psychological processes and conceptualize the term as an interpersonal phenomenon where the two persons care as well as think and feel. So that, they suggest that ethnocultural empathy to be defined as "feeling, understanding, and caring about what someone from another culture feels, understands, and cares about" [13]. According to Wang, et al. [1], ethnocultural empathy is a learned ability, and a personal trait that can be developed over time, which has three components; intellectual empathy, empathic emotions and communicative empathy. Intellectual empathy is the ability to understand how a person with a different ethnic background thinks or feels. Second component, the empathic emotions are attention to the feeling of a person or persons with a different ethnic background to the degree that one is able to feel the other's emotional condition from the point of view of that person's racial or ethnic culture. The communicative component is the expression of ethnocultural empathic thoughts and feelings toward person with a different ethnic background. In respect to study of Wang, et al. [1], Özdikmenli-Demir \& Demir [2] states that individuals with higher ethnocultural empathy level would behave more positively toward different ethnic group members, has the ability to perceive their feelings, shows respect for their traditions/languages, and protects them against discriminatory behaviors.

There are few instruments available for measuring cultural and ethnocultural empathy [14]. One is Multicultural Personality Questionnaire, which is developed by Van der Zee \& Van Oudenhoven [15], which includes a subscale of cultural empathy among the traits relevant to motivational, professional and occupational issues in a multicultural environment [14]. However, MPQ does not refer to the ability to empathize and communicate with others that are culturally and ethnically diverse [16]. The other one is Scale of Ethnocultural Empathy (SEE), developed by Wang, et al. [1], includes a crucial dimension; another person's "culture-oriented framework" in the experience of empathy [14] and aims to specifically measure ethnocultural empathy in late adolescents and adults [1]. Several studies have confirmed the factorial structure of SEE, the good psychometric properties and the validity across cultures [3], [14], [17].

Multicultural education, defined by Banks [18], as an idea, an education reform movement, aiming to transform the current structure of educational institutions so that both male and female students, students with disabilities, gifted students, and students who are members of different racial, ethnic, cultural groups have an equal chance to achieve academically in schools. Race, ethnic structure, language, gender, age, disability, social class, education, religious orientation and dimensions of other cultures are what multicultural education takes into consideration [19]. Multicultural education become imperative in the 21st century since ethnically homogeneous societies are reducing and nations' shifting to a more complex ethnic and cultural texture [20]. As can be seen clearly from the basic definitions above, multicultural education is closely related to ethnocultural empathy.

Besides being a lecturer, a contemporary teacher should have a number of competencies, abilities, knowledge, skills and personality traits to carry out required professional roles. In today's multicultural societies, multicultural competences appear to be one of these skills. Noting the culturally and ethnically heterogeneous structures of current educational settings, the European Commission [21] points out new demands on teaching profession and its requisition of not only acquiring new knowledge and skills but also developing them continuously. Atwater [22] states 
that the overall multicultural goal for all teachers, perhaps including the preservice teachers, is to learn how to discern, understand, and aid all students in the educational process.

Mostly because of the globalization and industrialization, diversity of students entering classrooms increases each day. And it becomes more necessary than ever for teachers to construct a positive classroom climate and culture. Salgur [23] identified six problems that teachers face when dealing students coming from different cultures; (1) believing equality and similarity of the all cultures, (2) language problems, (3) non-verbal communication, (4) having prejudices, discrimination and stereotypes about different cultures and people, (5) comparing the cultures and (6) being very stressful and anxious during the teaching process. Empathy, more specifically ethnocultural empathy, is an important competence in terms of being fundamental for building bridges between individuals, understanding other's emotions, gaining a diverse perspective, and empowering relationships for collaboration and progress. Thus, in today's multicultural society, ethnocultural empathy has become an important element in most educational settings and development of this competence has become more important than ever for educators in their interactions with students and their parents. With more ethnoculturally emphatic teachers, some of these issues identified by Salgur [23] could be prevented or reduced. Classroom teachers, are not only responsible for teaching the core curriculum but also teaching attitudes favorable to the nation and being a role model with their interactions both with their students and their parents.

In this context, aim of this study is to define and examine the ethnocultural empathy level of preservice classroom teachers. To help meet the purpose, research questions addressed in the study were: (1) what is the ethnocultural empathy level of preservice classroom teachers? (2) do preservice classroom teachers' ethnocultural empathy level differ by gender, grade level, ethnicity, mother tongue, parents' education level, family income, number of siblings, growth place and status of being experienced in multicultural environments? and (3) which factors predict ethnocultural empathy level?

\section{Method}

The research design of this study was non-experimental and causal-comparative, which seeks to find relationships between independent and dependent variables after an action or event has already occurred [24], as it studied the relationship between the pre-service classroom teachers' ethnocultural empathy level and demographics.

\subsection{Participants}

Participants were preservice teachers studying in
Primary School Education Programme in the Department of Elementary Education at Çanakkale Onsekiz Mart University in the academic year of 2017-2018 (see Table 1). A total of 434 preservice classroom teachers (155 males, 279 females) participated in this study.

Table 1. Demographics of the Participants

\begin{tabular}{ccccc}
\hline \multirow{2}{*}{ Grade Level } & \multicolumn{2}{c}{ Gender } & Total & $\%$ \\
\cline { 2 - 3 } & Male & Female & & \\
\hline $1^{\text {st }}$ Grader & 36 & 71 & 107 & $24.7 \%$ \\
$2^{\text {nd }}$ Grader & 36 & 69 & 105 & $24.2 \%$ \\
$3^{\text {rd }}$ Grader & 35 & 73 & 108 & $24.9 \%$ \\
$4^{\text {th }}$ Grader & 48 & 66 & 114 & $26.3 \%$ \\
Total & 155 & 279 & 434 & $100 \%$ \\
$\%$ & $35.7 \%$ & $64.3 \%$ & $100.0 \%$ & \\
\hline
\end{tabular}

Table 1 illustrates demographics of the participants. Of the 434 preservice classroom teachers, $279(64 \%)$ were female and $155(36 \%)$ were male. $24.7 \%$ of the participants were in their $1^{\text {st }}$ year, $24.2 \%$ of the participants were in their second year, $24.9 \%$ of the participants were in their third year and $36.3 \%$ of the participants were in their $4^{\text {th }}$ year. Most of the participants (61.8\%) defined themselves as Turkish, while some defined themselves as Kurdish (15.7\%). Mixed ethnic origins such as; Turkish-Kurdish, Turkish-Arabic, Arabic-Kurdish were 13.1\%, Circassian were $4.4 \%$, Arabic were $3.2 \%$; and Zaza were $1.8 \%$ of the participants. Majority of the participants' mother tongue was Turkish (78.1\%), and then Kurdish (17.5\%), Arabic (2.8\%), and Zazaish (1.6\%). $7.1 \%$ of the participants' mothers were literate, $53.7 \%$ of the mothers were primary school graduates, $14.5 \%$ elementary school graduates, $16.8 \%$ high school graduates, $7.6 \%$ university and $0.2 \%$ were graduate level graduates. Fathers of the participants were $1.2 \%$ literate, $40.8 .7 \%$ of the fathers were primary school graduates, $16.6 \%$ elementary school graduates, $27.9 \%$ high school graduates, $12.9 \%$ university and $0.7 \%$ were graduate level graduates. Participants generally came from low-income families; $42.6 \%$ of the participants' family wage was less than or equal to minimum wage. $3.7 \%$ of the participants were the only child in the family, $45.4 \%$ of them were from a family with 2 children, $26 \%$ were from a family with 3 children, $12.9 \%$ were from a family with 4 children and $12 \%$ were from a family with 5 or more children. $40.6 \%$ of the participants were firstborns, $25.3 \%$ were second child, $19.6 \%$ was third child and $14.5 \%$ of the participants were fourth or later born. $20.8 \%$ of the participants defined their selves as grown in a big city, $46.3 \%$ grown in city, $13.8 \%$ grown in a town and $11.8 \%$ grown in village or countryside. More than half of them $(51.3 \%)$ were living in dormitories $(30.6 \%$ public dormitory and 20.7 private dormitory), $40.6 \%$ were living with friends in a flat, while $7.2 \%$ were living with their families or relatives. 


\subsection{Data Collection Tool}

The data collection tool used in the study consisted of two sections. In the first section, there were 11 items for determining the demographics; gender, grade level, mother tongue, ethnicity, family income, number of siblings, birth order, mother's and father's education level, growth place, accommodation type of the participants. In the second section of the data collection tool, Turkish version of The Scale of Ethnocultural Empathy (TSEE), which was initially developed by Wang, et al. [1] and adopted to Turkish language by Özdikmenli-Demir \& Demir [2] was conducted to measure the ethnocultural empathy levels of preservice classroom teachers. TSEE consists of 30 items using a 5-point Likert-type scale ( $1=$ strongly disagree to $5=$ strongly agree). Adopted Turkish version of the SEE scale, along with the scoring instructions was provided by adopters. TSEE has 30 items and 3 factors/dimensions structure identified by the developer [2], namely; 'empathic feeling and expression' which is measured by 11 items, 'empathic perspective taking and acceptance of cultural differences' which is measured by 11 items and 'empathic awareness' which is measured by 8 items.

In order to determine the internal consistency of the scale and subscales, Cronbach's $\alpha$ values were calculated. For the entire TSEE, Cronbach's alpha was 0.866 , for the 'empathic feeling and expression' dimension Cronbach's alpha was 0.833 , for the 'empathic perspective taking and acceptance of cultural differences' Cronbach's alpha was 0.847 , and for the third dimension; 'empathic awareness' Cronbach's alpha was 0.865 . Regarding Cronbach's alpha's were reported in Özdikmenli-Demir \& Demir's [2] study as; 0.93 for the entire scale and $0.87,0.85$ and 0.81 for its three dimensions respectively.

\subsection{Data Collection and Analysis}

The data were collected on a voluntary basis by researcher in the classes of the preservice teachers. Then the responses of the participants entered to the statistical software; SPSS 22.0, where all other analysis; t-test, ANOVA and step-wise regression, were conducted. First, reverse coded items identified and reversed according the scoring instructions. Then mean scores of each dimensions and the entire scale were calculated. The Skewness and Kurtosis values were examined for the normality of the groups to be compared and found to be between -2 and +2 for each group which is sufficient for the use of parametric tests [25]. Therefore, parametric tests were used when comparing means.

\section{Findings}

In this section, the findings of the research are presented in tables and explained together with the results of the analysis.

\subsection{Ethnocultural Empathy Level of Preservice Classroom Teachers}

Descriptive statistics calculated to examine the ethnocultural empathy level of preservice classroom teachers.

Table 2 illustrates the ethnocultural empathy level of preservice classroom teachers. Preservice classroom teachers' mean score of ethnocultural empathy level was 4.31 on a 5-point Likert-type scale. Regarding the dimensions of ethnocultural empathy, mean scores of the participants were 4.30 for the 'empathic feeling and expression', 4.26 for the 'empathic perspective taking and acceptance of cultural differences' and 4.40 for the 'empathic awareness' dimension.

Table 2. Ethnocultural Empathy Level of Preservice Teachers

\begin{tabular}{cccc}
\hline & N & Mean & S.D. \\
\hline Total Scale & 434 & 4,31 & 0,45 \\
\hline $\begin{array}{c}\text { Empathic feeling and expression } \\
\begin{array}{c}\text { Empathic perspective taking and } \\
\text { acceptance of cultural } \\
\text { differences }\end{array}\end{array}$ & 434 & 4,30 & 0,48 \\
\hline Empathic awareness & 434 & 4,26 & 0,50 \\
\hline
\end{tabular}

\subsection{Analyzing Males and Females on Ethnocultural Empathy Level}

An independent samples t-test was conducted to compare the effect of gender on total ethnocultural empathy level and its dimensions; 'empathic feeling and expression', 'empathic perspective taking and acceptance of cultural differences' and 'empathic awareness'.

Table 3 illustrates the t-test results. There was a significant difference in ethnocultural empathy level of males $(\mathrm{M}=4.39, \quad \mathrm{SD}=0.40)$ and females $(\mathrm{M}=4.27$, $\mathrm{SD}=0.47) ; \mathrm{t}(432)=2.847, \mathrm{p}=0.005$.

Table 3. t-test Results Comparing Males and Females on Ethnocultural Empathy Level

\begin{tabular}{ccccccc}
\hline Gender & $\mathrm{N}$ & Mean & S.D. & $\mathrm{t}$ & $\mathrm{df}$ & $\mathrm{p}$ \\
\hline $\mathrm{m}$ & 155 & 4.39 & 0.40 & & & \\
$\mathrm{f}$ & 279 & 4.27 & 0.47 & & & \\
\hline
\end{tabular}

$*: \mathrm{p}<.05$

Significance differences also noted regarding the three dimensions of ethnocultural empathy. 'Empathic feeling and expression' level of males $(\mathrm{M}=4.38, \mathrm{SD}=0.41)$ significantly differed from females $(\mathrm{M}=4.25, \mathrm{SD}=0.51)$; $\mathrm{t}(432)=2.703, \mathrm{p}=0.007$. 'Empathic perspective taking and acceptance of cultural differences' level of males $(M=4.33$, $\mathrm{SD}=0.46)$ also significantly differed from females $(\mathrm{M}=4.22$, $\mathrm{SD}=0.51) ; \mathrm{t}(432)=2.255, \mathrm{p}=0.025$. There was also a significant difference in the 'empathic awareness' level of males $(\mathrm{M}=4.50, \mathrm{SD}=0.554)$ and females $(\mathrm{M}=4.35$, $\mathrm{SD}=0.60) ; \quad \mathrm{t}(432)=2.501, \quad \mathrm{p}=0.013$. Males total ethnocultural empathy level was higher compared to 
females. Males' level in all three dimensions of ethnocultural empathy were also higher than females.

\subsection{Analyzing Ethnocultural Empathy Level by Grade Level}

A One-way ANOVA was conducted to compare effect of grade levels on total ethnocultural empathy level and its subdimensions.

Table 4 illustrates the ANOVA results which showed that the effect of grade level on ethnocultural empathy level was significant $[\mathrm{F}(3,430)=32.998, \mathrm{p}=0.000]$.

Table 4. ANOVA Results Comparing Ethnocultural Empathy Level by Grade Level

\begin{tabular}{ccccccc}
\hline & $\begin{array}{c}\text { Sum of } \\
\text { Squares }\end{array}$ & df & $\begin{array}{c}\text { Mean } \\
\text { Square }\end{array}$ & F & p & Tukey \\
\hline $\begin{array}{c}\text { Between } \\
\text { Groups }\end{array}$ & 16.486 & 3 & 5.495 & & & $1-2$ \\
\cline { 1 - 4 } Within Groups & 71.609 & 430 & .167 & 32.998 & $.000 *$ & $1-3$ \\
$1-4$ \\
\hline Total & 88.095 & 433 & & & \\
\hline
\end{tabular}

$*: \mathrm{p}<.05 ; 1=1$ st grader, $2=2$ nd grader, $3=3 \mathrm{rd}$ grader, $4=4$ th grader

Regarding the subdimensions of the scale; significance differences were observed for each dimension. The effect of grade levels; on 'empathic feeling and expression' level was significant $[\mathrm{F}(3,430)=15.751, \mathrm{p}=0.000]$, on 'empathic perspective taking and acceptance of cultural differences' level was significant $[\mathrm{F}(3,430)=35.232, \mathrm{p}=0.000]$ and on 'empathic awareness' level was significant $[F(3,430)=24.455, p=0.000]$. Post hoc comparisons using the Tukey HSD test indicated that both the total ethnocultural empathy level and the three dimensions' level in $1^{\text {st }}$ graders were significantly lower than the other three grade levels.

\subsection{Analyzing Ethnocultural Empathy Level by Ethnicity}

A One-way ANOVA was conducted to compare effect of ethnic groups on total ethnocultural empathy level and its three subdimensions.

Table 5. ANOVA Results Comparing Ethnocultural Empathy by Ethnicity

\begin{tabular}{cccccc}
\hline & $\begin{array}{c}\text { Sum of } \\
\text { Squares }\end{array}$ & df & $\begin{array}{c}\text { Mean } \\
\text { Square }\end{array}$ & F & p \\
\hline Between Groups & 1.456 & 5 & .291 & & \\
Within Groups & 86.639 & 428 & .202 & 1.439 & .209 \\
Total & 88.095 & 433 & & & \\
\hline
\end{tabular}

$*: \mathrm{p}<.05$

Table 5 illustrates the ANOVA results conducted to compare the effect of ethnic groups on total ethnocultural empathy level. ANOVA results showed that the effect of ethnicity on ethnocultural empathy level was not significant $[\mathrm{F}(3,430)=1.439, \mathrm{p}=0.209]$.

Regarding the subdimensions, ANOVA also showed that the effect of ethnicity on 'empathic feeling and expression' level was not significant $[\mathrm{F}(3,430)=1.740$, $\mathrm{p}=0.124]$, the effect of ethnicity on 'empathic perspective taking and acceptance of cultural differences' level was also not significant $[\mathrm{F}(3,430)=1.384, \mathrm{p}=0.229]$ and the effect of ethnicity on 'empathic awareness' was not significant $[\mathrm{F}(3,430)=0.876, \mathrm{p}=0.497]$.

However, investigating the ethnic group differences by grouping the data into two; 1=majority group (Turks) and 2=Minority group (Kurd, Arab, Circassian, Zaza and mixed origins) and conducting a t-test to compare the mean scores of these two groups, revealed a significant difference in ethnocultural empathy level of Turks $(\mathrm{M}=4.28, \quad \mathrm{SD}=0.47)$ and others $(\mathrm{M}=436, \quad \mathrm{SD}=0.41)$; $\mathrm{t}(432)=-2.050, \mathrm{p}=0.041$.

Regarding the subdimensions of the scale; there was also a significant difference noted between Turks' 'empathic feeling and expression' level $(\mathrm{M}=4.26, \mathrm{SD}=0.50)$ and others $(\mathrm{M}=4.36, \quad \mathrm{SD}=0.44) ; \mathrm{t}(432)=-2.355, \mathrm{p}=0.019$. However, there was not a significant difference between Turks' 'empathic perspective taking and acceptance of cultural differences' level $(\mathrm{M}=4.23, \mathrm{SD}=0.51)$ and others $(\mathrm{M}=4.46, \mathrm{SD}=0.53) ; \mathrm{t}(432)=-1.273, \mathrm{p}=0.204$. There was also no significant difference found in the Turks' 'empathic awareness' level $(\mathrm{M}=4.36, \mathrm{SD}=0.62)$ and others $(\mathrm{M}=4.46$, $\mathrm{SD}=0.53) ; \mathrm{t}(432)=-1.757, \mathrm{p}=0.080$.

\subsection{Analyzing Ethnocultural Empathy Level by Mother Tongue}

A One-way ANOVA was conducted to compare effect of mother tongue on ethnocultural empathy level and its three subdimensions; 'empathic feeling and expression', 'empathic perspective taking and acceptance of cultural differences' and 'empathic awareness'.

Table 6. ANOVA Results Comparing Ethnocultural Empathy Level by Mother Tongue

\begin{tabular}{cccccc}
\hline & $\begin{array}{c}\text { Sum of } \\
\text { Squares }\end{array}$ & df & $\begin{array}{c}\text { Mean } \\
\text { Square }\end{array}$ & F & p \\
\hline Between Groups & .325 & 3 & .108 & & \\
Within Groups & 87.770 & 430 & .204 & .530 & .662 \\
Total & 88.095 & 433 & & & \\
\hline
\end{tabular}

$*: \mathrm{p}<.05$

Table 6 illustrates the ANOVA results conducted to compare the effect of mother tongue on ethnocultural empathy level. ANOVA showed that the effect of mother tongue on ethnocultural empathy level was not significant $[\mathrm{F}(3,430)=0.530, \mathrm{p}=0.662]$.

Regarding the subdimensions; effect of mother tongue on 'empathic feeling and expression' level was not significant $[\mathrm{F}(3,430)=0.351, \mathrm{p}=0.789]$, effect of mother tongue on the level of 'empathic perspective taking and acceptance of cultural differences' was not significant $[\mathrm{F}(3,430)=0.389, \mathrm{p}=0.761]$ and effect of mother tongue on the level of 'empathic awareness' was also not significant 
$[F(3,430)=0.526, p=0.665]$. Investigating the mother tongue differences by grouping the data into two; $1=$ majority group (Turkish) and 2=Minority group (Kurdish, Arabic, Circassian, Zazaish) and conducting a t-test to compare the mean scores of these two groups, did not also reveal a significant difference between the majority and the minority groups.

\subsection{Analyzing Ethnocultural Empathy Level by Parents' Education}

To investigate the effect of mother and father education on ethnocultural empathy level and its three subdimensions a one-way ANOVA was conducted.

Table 7. ANOVA Results Comparing Ethnocultural Empathy Level by Mother Education

\begin{tabular}{cccccc}
\hline & $\begin{array}{c}\text { Sum of } \\
\text { Squares }\end{array}$ & df & $\begin{array}{c}\text { Mean } \\
\text { Square }\end{array}$ & F & p \\
\hline Between Groups & 1.533 & 5 & .307 & & \\
Within Groups & 86.562 & 428 & .202 & 1.516 & .184 \\
Total & 88.095 & 433 & & & \\
\hline
\end{tabular}

$*: \mathrm{p}<.05$

Table 7 illustrates the ANOVA results comparing ethnocultural empathy level by mother education which showed that the effect of mother education on ethnocultural empathy level was not significant $[\mathrm{F}(5,428)=1.516$, $\mathrm{p}=0.184]$. There were also no differences observed regarding the effect of mother education on three subdimensions of ethnocultural empathy.

Table 8. ANOVA Results Comparing Ethnocultural Empathy Level by Father Education

\begin{tabular}{cccccc}
\hline & $\begin{array}{c}\text { Sum of } \\
\text { Squares }\end{array}$ & df & $\begin{array}{c}\text { Mean } \\
\text { Square }\end{array}$ & F & p \\
\hline Between Groups & .354 & 5 & .071 & & \\
Within Groups & 87.741 & 428 & .205 & .345 & .885 \\
Total & 88.095 & 433 & & & \\
\hline
\end{tabular}

$*: \mathrm{p}<.05$

Table 8 illustrates the ANOVA results comparing ethnocultural empathy level by father education which showed that the effect of father education on ethnocultural empathy level was not significant $[F(5,428)=0.345$, $\mathrm{p}=0.885]$. Regarding the subdimensions of ethnocultural empathy, there were also no differences observed regarding the effect of father education on three subdimensions of ethnocultural empathy.

\subsection{Analyzing Ethnocultural Empathy Level by Family Income}

A One-way ANOVA was conducted to compare the effect of family income on ethnocultural empathy level and its three subdimensions.
Table 9. ANOVA Results Comparing Ethnocultural Empathy Level by Family Income

\begin{tabular}{ccccccc}
\hline & $\begin{array}{c}\text { Sum of } \\
\text { Squares }\end{array}$ & df & $\begin{array}{c}\text { Mean } \\
\text { Square }\end{array}$ & F & P & Tukey \\
\hline Between Groups & 3.915 & 3 & 1.305 & & & $1-2$ \\
Within Groups & 84.180 & 430 & .196 & 6.666 & $.000 *$ & $1-3$ \\
Total & 88.095 & 433 & & & & $1-4$ \\
\hline
\end{tabular}

$*: \mathrm{p}<.05 ; 1=$ minimum wage or less, $2=$ minimum wage to $3000 \mathrm{TL}$ $3=3001$ to $5000 \mathrm{TL}, 4=5001 \mathrm{TL}$ and above

Table 9 illustrates the ANOVA results conducted to compare the effect of family income on ethnocultural empathy. Result of the analysis showed that the effect of family income on ethnocultural empathy level was significant $[\mathrm{F}(3,430)=6.666, \quad \mathrm{p}=0.000]$. Post hoc comparisons using the Tukey HSD test indicated that ethnocultural empathy level of participants whose coming from low income families $(\mathrm{M}=4.28, \mathrm{SD}=0.45)$ were significantly different than the other 3 groups; (1) participants whose coming from families that has 2001TL-3000TL income $(\mathrm{M}=4.40, \quad \mathrm{SD}=0.41)$, (2) participants whose coming from families that has 3001TL-5000TL income $(\mathrm{M}=4.15, \mathrm{SD}=0.52)$ and (3) participants whose coming from families that has 5001TL and above income $(\mathrm{M}=4.02, \mathrm{SD}=0.56)$.

Regarding the subdimensions; effect of family income on 'empathic feeling and expression' level was significant $[F(3,430)=6.209, p=0.000]$, effect of family income on 'empathic perspective taking and acceptance of cultural differences' level was significant $[\mathrm{F}(3,430)=4.439$, $\mathrm{p}=0.000$ ] and effect of family income on 'empathic awareness' level was also significant $[\mathrm{F}(3,430)=4.855$, $\mathrm{p}=0.000]$.

Tukey HSD tests regarding the subdimensions of ethnocultural empathy indicated that 'empathic feeling and expression' level of the participants whose coming from low income families $(\mathrm{M}=4.28, \quad \mathrm{SD}=0.50)$ were significantly different than the participants whose coming from families that has 5000TL and above income $(\mathrm{M}=3.93$, $\mathrm{SD}=0.50)$. 'Empathic feeling and expression' level of the participants whose coming from families that has $2001 \mathrm{TL}-3000 \mathrm{TL}$ income $(\mathrm{M}=4.40, \mathrm{SD}=0.41)$ significantly differed from the participants whose coming from families that has $3001 \mathrm{TL}-5000 \mathrm{TL}$ income $(\mathrm{M}=4.15, \mathrm{SD}=0.49)$ and the participants whose coming from families that has 5001TL and above income $(\mathrm{M}=4.30, \mathrm{SD}=0.48)$. 'Empathic perspective taking and acceptance of cultural differences' level of the participants whose coming from families that has $2000 \mathrm{TL}-3000 \mathrm{TL}$ income $(\mathrm{M}=4.34, \mathrm{SD}=0.46)$ also differed significantly from the participants whose coming from families that has 3001TL-5000TL income $(\mathrm{M}=4.10$, $\mathrm{SD}=0.58)$. 'Empathic awareness' level of the participants whose coming from low income families $(\mathrm{M}=4.35$, $\mathrm{SD}=0.55$ ) were significantly different than the participants whose coming from families that has 2001TL-3000TL income $(\mathrm{M}=4.51, \mathrm{SD}=0.55)$. 'Empathic awareness' level of the participants whose coming from families that has 
2001TL-3000TL income ( $M=4.50, \mathrm{SD}=0.55)$ significantly differed from the participants whose coming from families that has 3001TL-5000TL income $(\mathrm{M}=4.23, \mathrm{SD}=0.74)$ and the participants whose coming from families that has 5001TL and above income $(\mathrm{M}=4.13, \mathrm{SD}=0.80)$.

\subsection{Analyzing Ethnocultural Empathy Level by Number of Siblings}

A One-way ANOVA was conducted to compare effect of number of siblings on ethnocultural empathy level and its three subdimensions.

Table 10. ANOVA Results Comparing Ethnocultural Empathy Level by Number of Siblings

\begin{tabular}{cccccc}
\hline & $\begin{array}{c}\text { Sum of } \\
\text { Squares }\end{array}$ & df & $\begin{array}{c}\text { Mean } \\
\text { Square }\end{array}$ & F & P \\
\hline Between Groups & .998 & 4 & .249 & & \\
Within Groups & 87.097 & 429 & .203 & 1.229 & .298 \\
Total & 88.095 & 433 & & & \\
\hline
\end{tabular}

$*: \mathrm{p}<.05$;

Table 10 illustrates the ANOVA results conducted to compare the effect of number of siblings on ethnocultural empathy level. ANOVA showed that the effect of number of siblings on ethnocultural empathy level was not significant $[F(4,429)=1.229, \mathrm{p}=0.298]$.

Regarding the subdimensions of ethnocultural empathy; ANOVA showed that the effect of number of siblings on 'empathic feeling and expression' level was not significant $[F(4,429)=1.571, p=0.181]$, the effect of number of siblings on 'empathic perspective taking and acceptance of cultural differences' level was not significant $[\mathrm{F}(4,429)=0.957, \mathrm{p}=0.431]$ and the effect of number of siblings on 'empathic awareness' level was not also significant $[\mathrm{F}(4,429)=0.573, \mathrm{p}=0.682]$.

\subsection{Analyzing Ethnocultural Empathy Level by Birth Order}

To investigate the effect of birth order on ethnocultural empathy level and its three subdimensions a one-way ANOVA was conducted.

Table 11. ANOVA Results Comparing Ethnocultural Empathy Level by Birth Order

\begin{tabular}{cccccc}
\hline & $\begin{array}{c}\text { Sum of } \\
\text { Squares }\end{array}$ & df & $\begin{array}{c}\text { Mean } \\
\text { Square }\end{array}$ & F & P \\
\hline Between Groups & .673 & 3 & .224 & & \\
Within Groups & 87.422 & 430 & .203 & 1.103 & .348 \\
Total & 88.095 & 433 & & & \\
\hline
\end{tabular}

*: $\mathrm{p}<.05 ; 1=$ big city, $2=$ city, $3=$ town, $4=$ village or countryside

Table 11 illustrates the ANOVA results conducted to compare the effect of birth order on ethnocultural empathy level. ANOVA showed that the effect of birth order on ethnocultural empathy was not significant $[\mathrm{F}(3,430)=1.103$, $\mathrm{p}=0.348]$. There were also no significant differences observed regarding the effect of birth order on the three subdimensions of ethnocultural empathy.

\subsection{Analyzing Ethnocultural Empathy Level by Growth Place}

A One-way ANOVA was conducted to compare the effect of growth place on ethnocultural empathy level.

Table 12. ANOVA Results Comparing Ethnocultural Empathy Level by Growth Place

\begin{tabular}{cccccc}
\hline & $\begin{array}{c}\text { Sum of } \\
\text { Squares }\end{array}$ & df & $\begin{array}{c}\text { Mean } \\
\text { Square }\end{array}$ & F & P \\
\hline Between Groups & .665 & 3 & .222 & & \\
Within Groups & 87.430 & 430 & .203 & 1.090 & .353 \\
Total & 88.095 & 433 & & & \\
\hline
\end{tabular}

*: $\mathrm{p}<.05 ; 1=$ big city, $2=$ city, $3=$ town, $4=$ village or countryside

Table 12 illustrates the ANOVA results conducted to compare the effect of growth place on ethnocultural empathy. ANOVA showed that the effect of growth place of the participants on ethnocultural empathy level was not significant $[\mathrm{F}(3,430)=1.090, \mathrm{p}=0.353]$.

Regarding the subdimensions of ethnocultural empathy, analysis showed that; the effect of growth place on 'empathic feeling and expression' level was not significant $[F(3,430)=0.409, p=0.746]$, the effect of growth place on 'empathic perspective taking and acceptance of cultural differences' level was not significant $[F(3,430)=0509$, $\mathrm{p}=0.676]$. However, ANOVA showed that the effect of growth place 'empathic awareness' level was significant $[F(3,430)=4.639, p=0.003]$. Post hoc comparisons using the Tukey HSD test indicated that empathic awareness level of participants who grew up in village/countryside $(\mathrm{M}=4.14, \mathrm{SD}=0.59)$ was significantly different than the participants who grew up in big cities $(\mathrm{M}=4.49, \mathrm{SD}=0.57)$ and the participants who grew up in cities $(\mathrm{M}=4.41$, $\mathrm{SD}=0.60)$.

\subsection{Analyzing the Ethnocultural Empathy Level by Experience}

An independent samples t-test was conducted to compare effect of being experienced and non-experienced in multicultural environments on ethnocultural empathy.

Table 13. t-test Results Comparing the Experienced and Non-Experienced Participants on Ethnocultural Empathy Level

\begin{tabular}{|c|c|c|c|c|c|c|}
\hline Experienced & $\mathbf{N}$ & Mean & S.D. & $\mathbf{t}$ & df & $\mathbf{p}$ \\
\hline Yes & 221 & 4,52 & 0,28 & \multirow{2}{*}{11.420} & \multirow{2}{*}{432} & \multirow{2}{*}{$.000 *$} \\
\hline No & 213 & 4,09 & 0,49 & & & \\
\hline Yes & 221 & 4,45 & 0,41 & \multirow{2}{*}{7.082} & \multirow{2}{*}{432} & \multirow{2}{*}{$.000 *$} \\
\hline No & 213 & 4,14 & 0,50 & & & \\
\hline Yes & 221 & 4,49 & 0,36 & \multirow{2}{*}{11.064} & \multirow{2}{*}{432} & \multirow{2}{*}{$.000 *$} \\
\hline No & 213 & 4,02 & 0,51 & & & \\
\hline Yes & 221 & 4,67 & 0,41 & \multirow{2}{*}{11.201} & \multirow{2}{*}{432} & \multirow{2}{*}{$.000^{*}$} \\
\hline No & 213 & 4,12 & 0,61 & & & \\
\hline
\end{tabular}

$*: \mathrm{p}<.05$

Table 13 illustrates the t-test results conducted to 
compare the participants who have lived in a multicultural social environment and who lived in a homogeneous social environment. Result of the analysis showed that there was a significant difference in ethnocultural empathy level of the participants who have lived in a multicultural social environment $(\mathrm{M}=4.52, \mathrm{SD}=0.28)$ and who lived in a homogeneous social environment $(\mathrm{M}=4.09, \mathrm{SD}=0.49)$; $\mathrm{t}(432)=11.420, \mathrm{p}=0.000$.

Regarding the subdimensions of ethnocultural empathy; 'empathic feeling and expression' level of the participants who have lived in a multicultural social environment $(\mathrm{M}=4.45, \mathrm{SD}=0.41)$ significantly differed from who lived in a homogeneous social environment $(\mathrm{M}=4.14, \mathrm{SD}=0.50)$; $\mathrm{t}(432)=7.082, \mathrm{p}=0.000$. 'Empathic perspective taking and acceptance of cultural differences' level of the participants who have lived in a multicultural social environment $(\mathrm{M}=4.49, \mathrm{SD}=0.36)$ significantly differed from who lived in a homogeneous social environment $(\mathrm{M}=4.02, \mathrm{SD}=0.51)$; $\mathrm{t}(432)=11.064, \mathrm{p}=0.000$. 'Empathic feeling and expression' level of the participants who have lived in a multicultural social environment $(\mathrm{M}=4.45, \mathrm{SD}=0.41)$ also significantly differed from who lived in a homogeneous social environment $(\mathrm{M}=4.14, \mathrm{SD}=0.50)$; $\mathrm{t}(432)=7.082, \mathrm{p}=0.000$. Total ethnocultural empathy level along with its dimensions' level of experienced preservice teachers was higher compared to non-experienced preservice teachers.

\subsection{Analyzing the Predictors of Ethnocultural Empathy}

After examining the total ethnocultural empathy level and its subdimensions by independent variables of the study, a step-wise regression analysis was conducted to examine the relative contribution of independent variables to ethnocultural empathy.

Table 14 illustrates the results of step-wise regression that was conducted to predict ethnocultural empathy. A significant regression equation was found $[F(3,430)=64.362, p=0.000)]$, with an $R^{2}$ of 0.305 . The results of the regression analysis indicated the three predictors; being experienced in multicultural environments, grade level and being in the majority group (Turk), explained $30.5 \%$ of the variance in ethnocultural empathy.

Table 14. Step-wise Regression Predicting Ethnocultural Empathy

\begin{tabular}{cccccc}
\hline & $\begin{array}{c}\text { Sum of } \\
\text { Squares }\end{array}$ & df & $\begin{array}{c}\text { Mean } \\
\text { Square }\end{array}$ & F & p \\
\hline Regression & 27,299 & 3 & 9,100 & & \\
Residual & 60,795 & 430 &, 141 & 64.362 &, $000^{*}$ \\
Total & 88,095 & 433 & & & \\
\hline
\end{tabular}

$*: \mathrm{p}<.05$

Table 15 illustrates the coefficients of step-wise regression analysis results. These results showed that being experienced in multicultural environment $(\beta=0.391$, $\mathrm{p}=0.000$ ) emerged as the most significant predictor in the regression equation and it is alone accounted for $23.2 \%$ of the variation in ethnocultural empathy level. And then, the grade level $(\beta=0.260, \mathrm{p}=0.000)$ emerged as the second most significant predictor in the regression equation and it is accounted for an additional $6.9 \%$ of the variation in ethnocultural empathy level. Finally, status of being in the majority group (being Turk) $(\beta=0.096, p=0.018)$ was the third significant predictor in the regression equation and it is accounted for an additional $0.9 \%$ of the variation in ethnocultural empathy level. Other variables; gender, mother tongue, mother and father education level, family income, number of siblings, birth order, place of growth and accommodation, did not make a significant contribution to predicting satisfaction in the regression equation.

Table 15. Step-wise Regression Analysis Results (Coefficients)

\begin{tabular}{cccccc}
\hline Variable & $\mathbf{B}$ & $\mathbf{S E}(\mathbf{B})$ & $\boldsymbol{\beta}$ & $\mathbf{t}$ & $\mathbf{p}$ \\
\hline (Constant) & 4,509 &, 090 & & 50,316 &, 000 \\
Experienced &, 391 &, 037 &, 434 & 10,622 &, 000 \\
Grade level &, 104 &, 016 &, 260 & 6,360 &, 000 \\
Being Majority &, 089 &, 037 &, 096 & 2,383 &, 018 \\
\hline
\end{tabular}

$*: \mathrm{p}<.05$

\section{Discussion and Conclusions}

Aim of this study was to define and examine the ethnocultural empathy level of preservice classroom teachers. Most of the results in this study supported the cultural empathy, more specifically ethnocultural empathy literature.

To begin with, preservice teachers' ethnocultural level found to be above average on 5 point Likert-type scale which is slightly higher than the Özdikmenli-Demir \& Demir's [2] study which was conducted in sociology, philosophy, and statistics departments. Since participants of this study were preservice teachers and the teaching profession is highly related to altruistic behaviors, which also related to empathic behaviors [9], so this disparity between two studies could be interpreted as normal. However, more research should be conducted to understand what level of ethnocultural empathy is needed and adequate for teachers.

Gender differences; males were higher, found in this study is not completely in line with the relevant literature. Firstly, Özdikmenli-Demir \& Demir's [2] study states similar gender differences; in favor of males, on ethnocultural empathy levels of the university students. This maybe result of, as Özdikmenli-Demir \& Demir's [2] study reported, that males may have larger social networks composed of various peer groups from different ethnicities compared with female students. But, some other studies reported higher level of general empathy in females [26][29]. However, the concept of ethnocultural empathy is new in the field and there are not enough studies to 
completely compare this result and also it has some additional cognitive and emotional abilities to the general empathy [2].

Grade level differences observed in this study which was against 1st graders, is in line with the relevant literature. Rasoal, Eklund, \& Hansen [13] state that knowledge of other cultures and also experience with them should facilitate ethnocultural empathy. Understanding, which improves by experience, is also noted a central concept to empathy [9]. Considering that, young people become involved in new social environments and meet many people from various social, cultural, and ethnic backgrounds in college life [2] and so 1st graders are new and not much experienced in multicultural environments as the upper graders, this result of the study seems to be consistent with the literature. Being consisted with the literature, this study also found significant differences between the participants who have lived in a multicultural social environment and who lived in a homogeneous social environment; in favor of experienced ones.

Ethnicity differences identified in this study, which were against majority ethnic group, is also consistent with Özdikmenli-Demir \& Demir's [2] study. Wang et al. [1] and Segal et al. [30] reported similar empathy differences between majority group and minority ethnic groups [1], [30]. Since Turkish participants were the majority group both in the study and the country where this study conducted, they most likely do not face some discrimination and difficulties as the minority ethnic groups so that they have lower ethnocultural empathy level.

Regarding the predicting ethnocultural empathy level, only three predictors; 'being experienced in multicultural environments', 'grade level' and 'being in the majority group' showed significance in the regression equation in this study. This result is partially consistent with the literature. Zewdie, Tsion, Mirkuzie, \& Sudhakar [31] reported that being minority is a significant predictor of empathy while gender is not. Age is also reported as a significant predictor of the empathy, which may stand for grade level in this study, in Stanley, Buvaneswari, \& Meenakshi's [32] studies which aimed to identify predictors of empathy in women social workers [28].

Some cultural competency models states that having ethnocultural empathy does not mean being effective in interventions involving users, but is the first and fundamental step to achieve this [33]. Since, ethnically homogeneous societies are reducing and nations' shifting to a more complex ethnic and cultural texture [20] ethnocultural diversity is becoming more prevalent in educational settings. So that, it is important to consider inclusion or extension of ethnocultural empathy related subjects to curriculums. From this point of view, because of being future practitioners of curriculums, training ethnoculturally empathic' teachers is of great importance. Although there are remotely related courses and subjects within the four years of undergraduate study, teacher education programs in Turkey does not give any special importance to ethnocultural empathy competences. Cultural aspects should be considered when training future teachers. Although there is not enough scientific evidence that ethnoculturally empathic teachers would do better teaching, it is certain that teachers with inadequate ethnocultural empathy level will have problems in student and parent relations. Thus, for both reducing ethnocultural empathy level differences among gender, grade level and ethnicity identified in this study and improving teachers' interaction skills, specific courses could be provided or contents in related courses could be extended in teacher education curriculum.

This study has its own limitations like every other study. First, this article is based solely on quantitative data obtained through a self-report survey so that it may be expanded by conducting in-depth analysis via qualitative methods. Second limitation of this study is that sampling was used for data collection, so that, larger and heterogeneous sample derived from various universities and departments could have given a better understanding of the research questions and represent more valid and reliable results. In general, this study extends our knowledge on ethnocultural empathy and also preservice classroom teachers' ethnocultural empathic behaviors.

\section{REFERENCES}

[1] Y. W. Wang, M. M. Davidson, O. F. Yakushko, H. B. Savoy, J. A. Tan, and J. K. Bleier, "The Scale of Ethnocultural Empathy: Development, validation, and reliability," J. Couns. Psychol., vol. 50, no. 2, pp. 221-234, 2003.

[2] G. Özdikmenli-Demir and S. Demir, "Testing the Psychometric Properties of the Scale of Ethnocultural Empathy in Turkey," Meas. Eval. Couns. Dev., 2014.

[3] M. A. R. Brouwer and S. Boroş, "The Influence of Intergroup Contact and Ethnocultural Empathy on Employees' Attitudes toward Diversity," Cogn. Brain, Behav. An Interdiscip. J., vol. 14, no. 3, pp. 243-260, 2010.

[4] K. Gonzalez, "Cultural Empathy: Definitions and Examples," 2011. [Online]. Available: https://study.com/academy/less on/cultural-empathy-definition-examples.html\#lesson.

[5] H. Zhu, "From Intercultural Awareness to Intercultural Empathy," Lang. Teach., vol. 4, no. 1, pp. 116-120, 2011.

[6] P. S. Bellet and M. J. Maloney, "The Importance of Empathy as an Interviewing Skill in Medicine," JAMA J. Am. Med. Assoc., 1991.

[7] G. A. Gladstein, "Empathy and Counseling Outcome: An Empirical and Conceptual Review," Couns. Psychol., 1977.

[8] J. Håkansson, Exploring the phenomenon of empathy. 2003.

[9] J. Håkansson and H. Montgomery, "Empathy as an interpersonal phenomenon," J. Soc. Pers. Relat., vol. 20, no. 3, pp. 267-284, 2003. 
[10] M. L. Hoffman, "The contribution of empathy to justice and moral judgment," Reach. Out Caring, 1987.

[11] R. L. Bowman, "Review of Ivey, Ivey, and Simek-Morgan's Counseling and Psychotherapy: A Multicultural Perspective.," Counselor Education \& Supervision. 1994.

[12] C. R. Ridley and D. W. Lingle, "Cultural empathy in multicultural counseling: A multidimensional process model," in Counseling across cultures, J. E. Pedersen, P. B.; Draguns, J. G. ; Lonner, W. J.; Trimble, Ed. Thousand Oaks, CA, 1996, pp. 21-46.

[13] C. Rasoal, J. Eklund, and E. M. Hansen, "Toward a conceptualization of ethnocultural empathy," J. Soc. Evol. Cult. Psychol., vol. 5, no. 1, pp. 1-13, 2011.

[14] P. Albiero and G. Matricardi, "Empathy towards people of different race and ethnicity: Further empirical evidence for the Scale of Ethnocultural Empathy," Int. J. Intercult Relations, vol. 37, no. 5, pp. 648-655, 2013.

[15] K. I. van der Zee and J. P. van Oudenhoven, "The multicultural personality questionnaire: a multidimensional instrument of multicultural effectiveness," Eur. J. Pers., 2002.

[16] L. Leone, K. I. Van der Zee, J. P. van Oudenhoven, M. Perugini, and A. P. Ercolani, "The cross-cultural generalizability and validity of the Multicultural Personality Questionnaire,” Pers. Individ. Dif., 2005.

[17] C. Rasoal, T. Jungert, S. Hau, and G. Andersson, "Ethnocultural versus Basic Empathy: Same or Different?," Psychology, 2011.

[18] J. Banks, "Multicultural education: Characteristics and goals," in Multicultural education: Issues and perspectives, J. Banks and C. Banks, Eds. Boston: Allyn and Bacon, 1989, pp. 2-26.

[19] S. A. Salgur, "Multicultural education and teachers' characteristics," Euromentor J., vol. 6, no. 3, pp. 7-18, 2015.

[20] B. Lori, C. Assaf, R. Garza, and J. Battle, "Multicultural Teacher Education : in One Teacher Preparation Program," Teach. Educ. Q., vol. 37, no. 2, pp. 115-136, 2010.

[21] Commission of the European Communities,
"Communication From the Commission To the Council and The European Parliament - Improving the Quality of Teacher Education," 2007.

[22] M. M. Atwater, "Teacher education and multicultural education: Implications for science education research," J. Sci. Teacher Educ., vol. 7, no. 1, pp. 1-21, 1996.

[23] S. A. Salgur, Education for Democratic Citizenship and World Citizenship. Ankara: Lap Lambert Academic Publishing, 2014.

[24] N. J. Salkind, Encyclopedia of Research Design. Thousand Oaks, CA: SAGE Publications, 2010.

[25] A. Field, Discovering Statistics Using SPSS. 2005.

[26] S. Tavakol, R. Dennick, and M. Tavakol, "Empathy in UK medical students: Differences by gender, medical year and specialty interest," Educ. Prim. Care, 2011.

[27] L. Toussaint and J. R. Webb, "Gender differences in the relationship between empathy and forgiveness," J. Soc. Psychol., 2005.

[28] R. Wölfer, K. S. Cortina, and J. Baumert, "Embeddedness and empathy: How the social network shapes adolescents' social understanding," J. Adolesc., 2012.

[29] L. Rueckert, B. Branch, and T. Doan, "Are Gender Differences in Empathy Due to Differences in Emotional Reactivity?," Psychology, 2011.

[30] E. A. Segal, K. E. Gerdes, J. Mullins, M. A. Wagaman, and D. Androff, "Social empathy attitudes: Do latino students have more?," J. Hum. Behav. Soc. Environ., 2011.

[31] B. Zewdie, A. Tsion, W. Mirkuzie, and M. Sudhakar, "Predictors of perceived empathy among patients visiting primary health-care centers in central Ethiopia," Int. J. Qual. Heal. Care, 2012.

[32] S. Stanley, G. Mettilda Buvaneswari, and A. Meenakshi, "Predictors of empathy in women social workers," J. Soc. Work, 2018.

[33] V. Luque-Ribelles, P. Perez Moreno, A. Bocchino, M.-J. Albar, R. Garrido, and M. García-Ramírez, "Adaptation to spanish of an ethnocultural empathy scale," Texto Context. - Enferm., vol. 24, no. 3, pp. 621-628, 2015. 